\title{
A CROSS SECTIONAL STUDY OF SEXUAL BEHAVIOUR AND SOURCE OF INFORMATION ABOUT SEX AMONG UNDERGRADUATE MEDICAL STUDENT
}

\section{Neurology}

Parveen Kumar*

Resident doctor, Department of psychiatry, M.P. Shah Medical College, G.G Hospital Jamnagar, Gujarat, India Pin: 361008. *Corresponding Author

Nirav

\section{Bhupendrabhai Chanpa}

Senior resident, Department of psychiatry, M.P. Shah Medical College, department of psychiatry, G.G Hospital Jamnagar, Gujarat, India Pin: 361008.

\section{ABSTRACT}

Background: There are many myths and misconceptions about sexuality in India. Adolescent's sexual behaviors depend on their knowledge about sex, attitudes and sources of influence. Very few students can communicate about sexuality, and friends and pornographic materials remain as common sources of sex knowledge, which are unreliable.

Aims: The current study aimed to assess sexual behavior of undergraduate medical students and their source of information on sex.

Methodology: A cross sectional study was carried out to investigate the sexual behavior and their source of information on sex among undergraduate medical student Jamnagar, Gujarat. A Google document form was made and shared with all students from first year to internship comprising 850 students. The Google document contained structured questionnaire in three important parts: (1) Demographic details of students (2) Sexual behavior questionnaire (3) source of information about sex.

Results: Total 752 participants completed the survey. Around 76\% students engaged in masturbation. Very few participants indulge in sexual intercourse with sexual worker $(4.26 \%)$ or same sex partner, use of sexual aids $(1.5 \%)$, more than one partner $(9.7 \%)$ and anal sex $(10 \%) .42 .2 \%$ $(\mathrm{n}=317)$ participants acquire knowledge from phone or internet, $25.7 \%$ from newspaper, $19.9 \%$ from friends and only $2.4 \%$ from family member or relative.

Conclusion: Majority of participants indulged in sexual activity such as masturbation. Adolescents use Internet and newspaper as a major source of gathering information about sex. Sex education is also necessary because young people are unable to discuss their sexual concerns freely with family members.

\section{KEYWORDS}

Sexual behaviour, Source of information, Undergraduate, Medical student

\section{INTRODUCTION:}

There are different cultural values in different countries but adolescents maintain their sexual relationships in many ways. Adolescent's sexual behaviors depend on their knowledge about sex, attitudes and sources of influence. Adolescents indulge in different sexual behavior such as premarital sex, masturbation, watching pornography through phone and social networking sites. ${ }^{[1]}$ Studies found that only $17 \%$ of the adolescent population was aware of safe sex and $22 \%$ had the prior knowledge that intercourse may lead to pregnancy. ${ }^{[2]}$ An early age of initiation of sexual activity among adolescents poses a risk to sexual health in form of elevated rates of STDs and unplanned pregnancies. ${ }^{[3]}$ A substantial proportion of adolescents engaged in unwanted sexual activities do not receive appropriate care and education, which leads to adverse reproductive health outcomes. Adolescent's knowledge and awareness about sexual and reproductive health is increasing but this knowledge remains superficial. ${ }^{[4]}$ The early age of sexual activities among adolescents is influenced by many factors such as early age of sexual maturation, lack of knowledge about sex, declining cultural and religious influences and urbanization. ${ }^{[5]}$ Gender discrimination and stigma about discussing sex related issues among adolescents increasing risk taking behavior. ${ }^{\left[\sigma^{\circ}\right.}$ The current study therefore aimed to assess sexual behavior of undergraduate medical students and their source of information on sex.

\section{Method:}

A cross sectional study was carried out to investigate the sexual behavior of undergraduate medical students Jamnagar, Gujarat. A Google document form was made and shared with all students from first year to internship through email address and whatsapp group comprising 850 students. The Google document contained structured questionnaire in three important parts: (1) Demographic details of students (2) Sexual behavior questionnaire (3) source of information about sex. Participants who did not respond to the questionnaire were sent three reminders at a gap of 3 days. Participants who gave consent and filled the form were included in study. Ethical approval was taken from the institutional ethical committee.

\section{Material}

Sociodemographic data: A Google sheet was used to collect details such as age, gender, religion, education, occupation, relationship status and socioeconomic status.
Sexual Behavior questionnaire involving self or others ${ }^{171}$ : This questionnaire was developed by Dutt et al. and used to assess to sexual behavior of participants. It consists of 15 questionnaire such as; 'engaged in Masturbation', 'Kissing of neck and ears', 'Dry kiss on the mouth', 'Touch breasts with hands', with response of "yes" or "no".

Source of information about sex: Participants were asked about their different sources of information about sex, such as internet/mobile, newspaper, friends, parents, movies and other relatives.

\section{RESULTS:}

Data entry and analysis was done using Microsoft excel software. The socio-demographic profile and details of sexual behaviors have been expressed in terms of frequency and percentage.

Total 752 participants completed the survey. Participant's age ranged from 18-26 years with mean age of $20.63 \pm 1.46$ years. Most of participants $(95 \%)$ belonging to Hindu religion. Out of total respondents $64 \%$ were male and $36 \%$ females.

Table 1: Response rate on sexual behavior $(\mathrm{N}=752)$

\begin{tabular}{|l|l|l|l|}
\hline $\begin{array}{l}\text { Sr } \\
\text { no. }\end{array}$ & Sexual behavior questionnaire & \multicolumn{2}{|l|}{$\begin{array}{l}\text { Participants engaged in } \\
\text { sexual behavior }\end{array}$} \\
\hline & & Number (N) & Percentage \\
\hline 1 & Engaged in Masturbation & 573 & $76.20 \%$ \\
\hline 2 & Kissing of neck and ears & 334 & $44.41 \%$ \\
\hline 3 & 'Dry' kiss on the mouth & 318 & $42.29 \%$ \\
\hline 4 & French kiss (with tongue) & 306 & $40.70 \%$ \\
\hline 5 & Touch breasts with hands & 293 & $38.96 \%$ \\
\hline 6 & Touch male/female sexual organs & 270 & $35.90 \%$ \\
\hline 7 & $\begin{array}{l}\text { Engaged in sexual intercourse with } \\
\text { same sex partners }\end{array}$ & 08 & $01.06 \%$ \\
\hline 8 & $\begin{array}{l}\text { Engaged in sexual intercourse with } \\
\text { opposite sex partners }\end{array}$ & 174 & $23.14 \%$ \\
\hline 9 & Indulge in oral sex & 155 & $20.61 \%$ \\
\hline 10 & Indulge in anal sex & 76 & $10.11 \%$ \\
\hline 11 & Use sexual aids (vibrator, etc.) & 11 & $01.46 \%$ \\
\hline 12 & $\begin{array}{l}\text { Use contraceptive or safe sex } \\
\text { precautions }\end{array}$ & 264 & $35.11 \%$ \\
\hline \multicolumn{2}{|l|}{ International Journal of Scientific Research } & \multicolumn{2}{|c|}{6} \\
\cline { 2 - 3 }
\end{tabular}




\begin{tabular}{|l|l|l|l|}
\hline 13 & $\begin{array}{l}\text { Indulge in sexual activity with more than } \\
\text { one partner }\end{array}$ & 73 & $09.71 \%$ \\
\hline 14 & $\begin{array}{l}\text { Engage in sexual intercourse with } \\
\text { commercial sex workers }\end{array}$ & 32 & $04.26 \%$ \\
\hline 15 & Mutual masturbation & 130 & $17.29 \%$ \\
\hline
\end{tabular}

Around three forth of students engaged in masturbation. Very few participants indulge in sexual intercourse with sexual worker or same sex partner, use of sexual aids, more than one partner and anal sex. The percentage of youth reporting indulgence in sexual behaviors across various subsections is presented in Table 1.

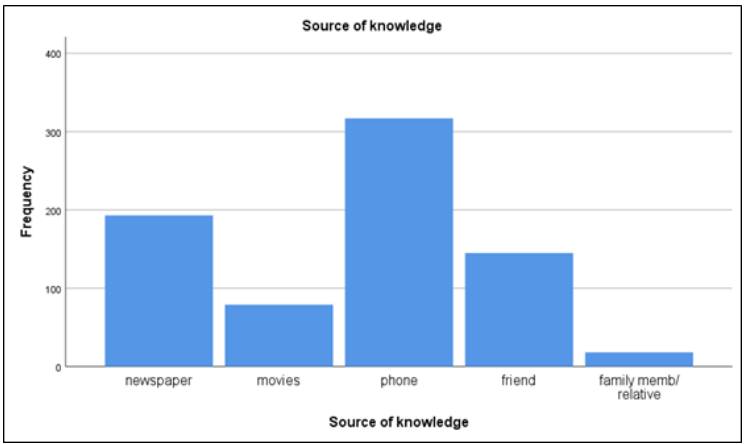

Figure 1: Different sources used by participants for sex knowledge

Figure 1 shows different sources of information about sex. In current study $42.2 \%(\mathrm{n}=317)$ participants acquire knowledge from phone or internet, $25.7 \%$ from newspaper, $19.9 \%$ from friends and only $2.4 \%$ from family member or relative.

\section{DISCUSSION:}

In current study $23 \%$ students reports indulge in sexual intercourse. Kaur et al (1996) in a study among college students report $19 \%$ prevalence rate of premarital sex. ${ }^{[8]}$ Sharma et al (2001) reports that more than quarters of participants have premarital sex. ${ }^{[9]}$ Aggarwal et al (2000) in study among medical college girl students from India reports $11.8 \%$ experienced sexual intercourse. ${ }^{[10]}$ In current study $76 \%$ students reported as doing masturbation, which are consistent with findings of Mukherjee et al (2019) reports one third of participants doing masturbation. ${ }^{[11]}$ Sachdev et al (1998) in study among university students and Sharma et al (2001) reports $80 \%$ prevalence of masturbation ${ }^{[12]}$ Current study found $20 \%$ prevalence of oral sex. Dutt et al $(2017)^{[7]}$ observed $8 \%$, while Avasthi et al $(2008)^{[13]}$ found $10 \%$ prevalence of oral sex. The difference in observation may be due to different study population. Current study found that very few participants indulge in sexual intercourse with sexual worker or same sex partner, use of sexual aids, more than one partner and anal sex. Study results are consistent with Dutt et al (2017); found average score falls under the category of low level of indulgence. ${ }^{[7]}$ A study by Abraham et al (1999) from Mumbai among college students observed that $26 \%$ of young men and $3 \%$ of young women reported penetrative sex, while other forms of physical intimacy such as kissing and touching reported by 49 and $13 \%$, respectively. ${ }^{[14]}$

The current study observed low level of indigence in sexual behavior with self or others, sexual intercourse with commercial sex workers, sexual intercourse with same sex partners and sexual activity with more than one partner. These results are consistent with findings by Dutt et al. ${ }^{[7]}$ Study by Smith et al (2003) at Australia found that $8.6 \%$ of women and $5.9 \%$ of men reported some homosexual sexual experience in their lives, finding suggest that homosexual attraction and orientation across different cultures may be similar. ${ }^{[15]}$

Study by Joshi et al (2010) found the peers, books and magazines were the most frequently used sources of information about sex. ${ }^{\left[{ }^{[1]}\right.}$ Due to easy access to internet and new media technologies such as cell phones have made sexually explicit materials more accessible to young people. The current study found that phone/internet $(42.2 \%)$ and newspaper $(25.7 \%)$ were frequent sources of information about sex followed by friends (20\%). Similarly study by Dutt et al (2017) among college youth found that participants acquire sex knowledge from unreliable sources such as internet, newspapers and friends and very few students take advice from parents or other family members. ${ }^{[]}$ Media plays important role in determining early sexual activity among adolescent. ${ }^{[16]}$ Young people may develop unrealistic ideas about and/ or undesirable patterns of sexual behavior due to increased accessibility of explicit sexual content. ${ }^{[17]}$

\section{CONCLUSION:}

Majority of participants indulged in sexual activity such as masturbation. While very few were in risky sexual behavior such as intercourse with same sex partners, more than one partner, intercourse with commercial sex workers and Use sexual aids. Adolescents use Internet and newspaper as a major source of gathering information about sex. Sex education is also necessary because young people are unable to discuss their sexual concerns freely with family members. There are areas of sex knowledge and attitude which need improvement by proper sex education.

\section{LIMITATIONS:}

Self reported data in study could be biased in the direction of both overreporting and underreporting. The study participants were from the same college and from a higher family income group with similar socioeconomic class. So findings of the study cannot be generalized.

\section{REFERENCES:}

1. Joshi B, Chauhan S. Determinants of youth sexual behaviour: program implications for India. East J Med 2011;16:113-21

2. Kumar A, Tiwari VK. Knowledge, attitude and behaviour towards pre-marital sex: a study among youths from two cityslums in India. J Health Popul 2003;26:126-34.

3. Barone C, Ickovics JR, Ayers TS, Katz SM, Voyce CK, Weissberg RP. High-risk sexual behavior among young urban students. Fam Plan Perspect 1996;28:69-74.

4. Jejeebhoy SJ, Sebastian MP. Actions that protect: promoting sexual and reproductive health and choice among young people in India. New Delhi Population Council. 2003.

5. Falaye AO. Predictive factors influencing the sexual behaviour of some Nigerian adolescents. IFE Psychologia 2004:12:17-26

6. Miller KS, Whitaker DJ. Predictors of mother-adolescent discussions about condoms: implications for providers who serve youth. Pediatrics 2001;108:E28

7. Dutt S, Manjula M. Sexual knowledge, attitude, behaviors and sources of influences in Urban college youth: A study from India. Indian Journal of Social Psychiatry. 2017 Oct 1;33(4):319.

8. Kaur U, Sahni SP, Bambery P, et al. Sexual behaviour, drug use and hepatitis B infection in Chandigarh students. Natl Med J India. 1996;9(4):156-159.

9. Sharma R. More than a quarter of India's youngsters have premarital sex. BMJ. 2001 Mar 10;322(7286):575

10. Aggarwal O, Sharma AK, Chhabra P. Study in sexuality of medical college students in India. J Adolesc Heal. 2000;26(3):226-229

11. Mukherjee A, Gopalakrishnan R, Thangadurai P, Kuruvilla A, Jacob KS. Knowledge and Attitudes toward Sexual Health and Common Sexual Practices among College Students - A Survey from Vellore, Tamil Nadu, India. Indian J Psychol Med. 2019;41(4):348-56.

12. Sachdev P. Sex on campus: a preliminary study of knowledge, attitudes and behaviour of university students in Delhi, India. J Biosoc Sci. 1998 Jan;30(1):95-105.

13. Avasthi A, Kaur R, Prakash O, Banerjee A, Kumar L, Kulhara P. Sexual behavior of married young women: A preliminary study from North India. Indian J community Med. 2008:33(3):163-167.

14. Abraham L, Kumar KA. Sexual experiences and their correlates among college students in Mumbai City, India. Int Fam Plan Perspect 1999;139-52.

15. Smith A, Rissel CE, Richters J, Grulich AE, Visser RO. Sex in Australia: the rationale and methods of the Australian Study of Health and Relationships. Aust N Z J Public Health 2003;27:106-17

16. Village EG. American Academy of Pediatrics. Policy statement- sexuality, contraception, and the media. Pediatrics 2010;126:576-82

17. Nathan D, Pornography. Toronto, Canada: Groundwork Books; 2007. 